\title{
Descolonización y cine: la propuesta indígena de Jorge Sanjinés hoy
}

\author{
Núria Vilanova \\ American University
}

\begin{abstract}
This article explores the legacy of Jorge Sanjinés' cinema in current Latin American cinematography, specifically in Bolivia. The central idea argues that despite the favourable political situation Bolivia is at the present experiencing, with the arrival of Evo Morales to the Presidency in the year 2006, the declaration of Bolivia as a multinational State, and the growing prominence of aymaras and quechuas in the national political arena, indigenous film as envisioned by Sanjinés has not been fully developed. The article puts forward the difficulties which the national and international film industry face in incorporating a type of film that does not respond to the expectations of a mainstream public, makes no concessions to the Western viewer, and provides no cultural filters to pave the viewer's understanding and persuade him or her cinematically.
\end{abstract}

\section{Keywords}

CEFREC, film industry, Insurgentes (2012), La nación clandestina (1989), Sanjinés' film theory, aesthetics and narrative, Yawar Mallku (1969) 


\section{Resumen}

Este artículo explora la herencia del cine de Jorge Sanjinés en el cine latinoamericano actual y muy específicamente en el boliviano. La idea central argumenta que a pesar de la favorable coyuntura política que vive Bolivia con la llegada de Evo Morales a la presidencia en el año 2006, la declaración de Bolivia como un Estado plurinacional y el creciente protagonismo de aymaras y quechuas en la esfera política nacional, el cine indígena, como lo vislumbró Sanjinés, no se ha desarrollado lo suficiente. El artículo plantea la dificultad de lograr que la industria cinematográfica nacional e internacional sea capaz de incorporar un tipo de películas que no responde a las expectativas de un público convencional más o menos mayoritario, que no hace concesiones al espectador occidental ni recurre a los filtros necesarios para allanar su comprensión y persuadirle cinematográficamente.

\section{Palabras claves}

CEFREC, industria cinematográfica, Insurgentes (2012), La nación clandestina (1989), teoría, estética y narrativa cinematográfica de Sanjinés, Yawar Mallku (1969)

A principios de los años noventa, en una pequeña filmoteca de Ginebra se proyectaba La nación clandestina (Sanjinés 1989). Un reducido público, simpatizante con películas minoritarias que se acercan a otras culturas y realidades, se mantuvo fiel en sus asientos las más de dos horas en las que transcurre el film boliviano. El silencio de la sala era de respeto y admiración, pero también medía la profunda distancia entre el complejo y contradictorio mundo del aymara Sebastián Mamani, el protagonista, y la vida de los que acudimos a ver la película. La nación clandestina gozó de un gran éxito cuando salió a la luz, ganando importantes premios cinematográficos, entre otros, la Concha de Oro en el Festival Internacional de Cine de San Sebastián, España, en 1989. Si bien el reconocimiento a esta obra maestra de Sanjinés ha sido unánime, también es cierto que ésta es una película, como la mayoría de las que componen la obra del cineasta boliviano, que sigue circunscrita a un ámbito reducido de cinéfilos que, si bien logran captar la calidad innovadora de la narrativa que Sanjinés forja para armonizar la cosmovisión aymara y el arte cinematográfico, siguen en general alejados de una propuesta tan inno- 
vadora como críptica para la mirada occidental. ${ }^{1}$

Tomando como trasfondo La nación clandestina, este artículo se propone explorar la herencia del cineasta en el actual cine latinoamericano, más específicamente, en el cine boliviano. La idea central planteada en estas páginas argumenta que, a pesar de la favorable coyuntura política, con la llegada del presidente Morales en el año 2006 y la declaración de Bolivia como un Estado plurinacional, el cine indígena, como lo vislumbró Sanjinés, no se ha desarrollado suficientemente, teniendo en cuenta el impulso innovador y de ruptura que tuvo en su momento y el creciente protagonismo de aymaras y quechuas en la esfera política nacional. Sin embargo, sí ha habido grandes avances en el desarrollo de proyectos audiovisuales que han dado representación y voz a muchas comunidades de los pueblos originarios andinos. Con lo cual, la hipótesis que este trabajo quiere avanzar es que el uso de herramientas audiovisuales de conocimiento y representación de las realidades indígenas quedan confinadas a la esfera de proyectos que circulan por los márgenes de la industria cinematográfica, en lugar de entrar plenamente integrados en ella. Sin duda, las iniciativas audiovisuales que Bolivia encabeza en el contexto latinoamericano son de un gran valor y han proporcionado un espacio único de comunicación y representación. Sin embargo, lo que aquí se plantea es la dificultad de lograr que la industria cinematográfica nacional e internacional sea capaz de incorporar un tipo de películas -con su narrativa y técnica propias- que no responde a las expectativas y gustos de un público más o menos mayoritario, al no limar en clave occidental aquellos aspectos más inaccesibles fuera del ámbito cultural de los pueblos originarios. Subyace en este análisis la pregunta que tanto se han hecho los estudios culturales acerca de si la subalternidad tiene voz, y esta voz a quién representa y quién la escucha, cuestión formulada por

\footnotetext{
${ }^{1}$ Mientras estoy finalizando este artículo, se da la increíble coincidencia de que anoche, 8 de diciembre 2012, se presentó en Madrid la última película de Sanjinés, Insurgentes, con la presencia del presidente Morales. Ya se había estrenado en Bolivia hace unos meses. Lamentablemente, la distancia no me permitió acudir a esta importante cita, pero no me queda ninguna duda que esta película pasa a ser esencial en la carrera cinematográfica del gran cineasta boliviano al proyectar la historia de Bolivia asumiendo que la llegada de Morales al poder es la culminación de un proceso mediante el cual las reivindicaciones de las películas anteriores se ven cumplidas. Al final del artículo retomaré esta última película del cineasta boliviano.
} 
Gayatri Chakravorty Spivak en su artículo fundacional, "Can the Subaltern Speak?", del año 1983. A modo introductorio, se puede afirmar que Sanjinés, en la misma línea que Spivak, entenderá que no hay otra posibilidad de representación (re-presentación para Spivak) de los pueblos aymara y quechua que la de su propia proyección, sin mediadores, en el caso que nos ocupa, solamente a través de la cámara cinematográfica. Conseguir que la cámara se ponga al servicio total de los personajes/actores para re-presentar a estos pueblos conformará el trabajo que moldea toda la obra del cineasta boliviano.

La singularidad de Bolivia en su desarrollo sociocultural, marcada por la compleja pero, a la vez, prolífera combinación de aymaras, quechuas, mestizos y criollos, entre otros grupos étnicos de su geografía, se refleja, como en tantos otros ámbitos de la vida boliviana, en el surgimiento de su industria cinematográfica. Si bien México, Argentina y Brasil se consolidaron desde los años treinta del siglo XX como las tres grandes potencias cinematográficas de América Latina, a las que más tarde se añadiría Cuba y, en años recientes, otros países como Chile y Perú, Bolivia experimentó un fenómeno único y extraordinario que trascendió las fronteras nacionales y puso al país en el mapa cinematográfico latinoamericano e internacional desde, aproximadamente, la década de los años sesenta. Se trata de la experiencia materializada en películas de renombre internacional como Yawar Mallku (1969) o La nación clandestina (1989), que llevaron a la pantalla grande la cosmovisión, la resistencia y la lucha de quechuas y aymaras del altiplano andino desde una nueva narrativa estética y política. El grupo Ukamau, cuyo nombre significa en aymara "!así es!", y del que fue máximo exponente Jorge Sanjinés, director de las películas mencionadas, tuvo como objetivo romper la barrera entre la cámara fílmica y el mundo indígena que ésta quería captar, plasmar y representar, con el firme propósito de acercarse a este universo hasta penetrar en las entrañas andinas desde dentro de sí mismas.

El contexto político de la revolución de 1952 y de los años sucesivos es imprescindible para comprender con cierta perspectiva este fenómeno cinematográfico. La revolución del 52, a pesar de sus ideales inconclusos de reformas económicas profundas en el campo y la minería, y de democracia participativa, será sin duda el desencadenante de una creciente participación popular en un entorno social y cultural, en el que el mundo indígena ha destacado históricamente por su capacidad de persistencia y resistencia en la lucha por sus derechos. Sin duda, como ocurrirá en México, y más tarde en Cuba, la cinematografía servirá como vehículo primordial de comunicación y 
propagación de ideas y mensajes políticos. En este sentido, hay que tener en cuenta el poder visual y hegemónico del cine en América Latina (México, Brasil y Argentina, principalmente) en la décadas de los años 40 y 50, en una época en que la expansión de las nuevas tecnologías, que más tarde revolucionarán el propio concepto de lo visual y comunicativo, como Internet y las redes sociales, no son todavía ni siquiera un proyecto imaginable.

Hay muchos ejemplos de la fuerza persuasiva que exhibió el cine desde los años treinta, con la incorporación del sonido a la imagen. Recordemos el impacto de las legendarias películas que mostraban un México idílico a través del cual se quería transmitir el anhelo de una sociedad armoniosa y estable, que, tras los violentos años de la Revolución mexicana de 1910, la propia gesta revolucionaria había creado en el imaginario nacional y que, a nivel simbólico, consolidaba el ansiado proyecto de una modernidad que coexistiera fraternalmente con la tradición, y que estuviera basada en la igualdad y la democracia. Películas como Allá en el Rancho Grande (1936), que inauguran la llamada época de oro del cine mexicano y el popular género de comedias rancheras, proliferaron durante la década de los años cuarenta, de la misma manera que lo harían las famosas películas argentinas, como Melodía de arrabal (1932) y El día que me quieras (1935), que lanzaron al inmortal Carlos Gardel a la pantalla grande. Además, hay que tener en cuenta también el impacto de Hollywood, que en esos años se está consolidando como la gran potencia cinematográfica mundial, y que tan estrechamente colaborará con la política del "buen vecino", del presidente Franklin Delano Roosevelt (1933-1945), ${ }^{2}$ produciendo películas cargadas de propaganda política como Juárez (1939), en la que, legendarios actores como Greta Garbo y Paul Muni, interpretan la historia de Benito Juárez, cuando en 1863, recién elegido primer presidente de origen indígena de México, debe salir al exilio, hasta la frontera norte con los Estados Unidos, debido a la llegada del

\footnotetext{
2 La política del "buen vecino" fue inaugurada por el presidente F.D. Roosevelt para replantear las relaciones de Estados Unidos con América Latina, tras el impacto negativo que la "Doctrina Monroe", de James Monroe, aunque formulada por John Quincey Adams, en 1823, había tenido con la enmienda que en el año 1924 promulgó el entonces presidente estadounidense Theodore Roosevelt. Mediante el llamado "corolario Roosevelt", Estados Unidos pasaba de salvaguardar el continente americano (se entiende tanto Norte América, como América Central y del Sur) de cualquier invasión europea europea -como originalmente reza la Doctrina Monroe- a erigirse como claro poder intervencionista hacia sus vecinos del sur.
} 
emperador Maximiliano enviado por Napoleón III para mantener control sobre su país. La admiración de Juárez hacia el presidente estadounidense Abraham Lincoln, y los estrechos lazos de amistad que unían a ambos países en aquel momento, son melodramáticamente explotados en la pantalla en el paradigmático año de 1939, en que se produce la película, cuando la Segunda Guerra Mundial es ya una realidad y los Estados Unidos necesitan afianzar a México en el bloque de los Aliados. Esta complicidad bélica y política de América Latina con los países Aliados va a ser un aspecto crucial de la doctrina del "buen vecino", que claramente se va a trasladar al cine. Otra celebración de la amistad entre los países de América Latina se dará a través de películas como That Night in Rio (1941) que, en plena guerra, proyecta una explosión de colorido y festividad para celebrar a otro gigante latinoamericano, Brasil, de la mano de la también celebrada Carmen Miranda. Aunque un análisis detallado de estas películas mostraría con claridad la supremacía tanto cultural, como económica, social y política, con la que Estados Unidos se proyectaba a través de ellas, a primera vista, y para el gran público de la época, éstas eran grandes producciones cinematográficas que rememoraban los lazos de amistad entre Estados Unidos y sus vecinos latinoamericanos.

Sin duda, el cine fue, desde los años treinta y a lo largo de la segunda mitad del siglo XX, un medio poderoso y un instrumento efectivo de transmisión de ideas y de proyección de imágenes que trasladaban visualmente agendas políticas diversas a un público que descubría los placeres de esta forma sutil y atractiva de entretenimiento colectivo. En este sentido, también es imprescindible, al contextualizar el cine de Ukamau y Sanjinés, tener en cuenta otras propuestas paralelas a las de los cinematógrafos bolivianos, que se van a dar simultáneamente en América Latina, con directores como Fernando Solanas (1936), en Argentina, Miguel Littín (1942), en Chile, Glauber Rocha (1939-1981), en Brasil, Tomás Gutiérrez Alea (1928-1996), en Cuba. Sus proyectos crearán, cada uno con su propio estilo y en base a la propia realidad y coyuntura nacional, un cine de denuncia y movilización política, comprometido e innovador, en el contexto latinoamericano. En este sentido, es imprescindible mencionar el gran antecedente de esta corriente realista y de compromiso político y social, la obra clave de Luis Buñuel, Los olvidados (1950) que, si bien supuso un golpe inaceptable para una gran parte de la sociedad mexicana, acostumbrada a la boyante industria nacional de melodramas rancheros, sin duda desenmascaró la cruda realidad económica y social de países, como el propio México, que estaban entrando a la 
modernidad a partir de un desarrollo profundamente desigual tanto en lo económico como socialmente. ${ }^{3}$ Los olvidados, con su dimensión surrealista, utilizará las mismas técnicas del neorrealismo italiano para trasladar a la gran pantalla y, por lo tanto, al gran público, las profundas y enquistadas injusticias sociales que caracterizaban y todavía caracterizan, a pesar de los grandes avances, a la sociedad mexicana. ${ }^{4}$

Como ha sido dicho anteriormente, el propósito de este artículo, que forma parte de un proyecto más amplio para el estudio de las representaciones indígenas en el cine latinoamericano, es explorar la evolución del cine fundacional de Jorge Sanjinés y el grupo Ukamau a lo largo de los años, su impacto en la cinematografía boliviana actual y establecer, en la medida de lo posible, paralelismos con propuestas actuales de índole semejante. Por supuesto, es imprescindible en este análisis tener en cuenta el contexto político de cambio que experimenta Bolivia en la actualidad con el gobierno del presidente Evo Morales, muchas de cuyas políticas pretenden sacudir y transformar directamente las bases del sistema establecido. La primera hipótesis, a riesgo de que sea todavía demasiado prematura, es esbozar, que si bien el grupo Ukamau inició una corriente cinematográfica cuyo objetivo era desarrollar un cine de pleno compromiso con los mundos quechua y aymara, trasladando a la pantalla grande mensajes de denuncia y cambio

${ }^{3}$ La película supuso un fuerte varapalo para el gobierno mexicano que mediante el Partido Revolucionario Institucional se había instalado cómodamente en el poder proyectando hacia la sociedad la imagen de un país moderno que había logrado superar y sanar sus grandes brechas e históricas diferencias en una catártica y legendaria Revolución (1910-1924). Los olvidados ponía al descubierto las profundas fisuras del sistema y las crecientes desigualdades sociales. La película fue duramente criticada desde diversos sectores que abominaban del atrevimiento de alguien como Buñuel que se atrevía a mostrar un México con el que la mayor parte de la sociedad no se reconocía o no quería reconocerse. La película fue censurada en un primer momento, pero los años la han convertido en una de las obras más celebradas y emblemáticas de la cinematografía mundial.

${ }^{4}$ Los olvidados incorpora elementos surrealistas, como la emblemática escena del sueño de Pedro y la simbólica aparición del gallo negro a lo largo de la película, a un esquema neorrealista general, que comparte el mismo espíritu que empujó a cineastas como Vittorio De Sica a crear una estética y una narrativa cinematográficas que fueran una herramienta de denuncia política y social. El uso del blanco y negro, de actores no profesionales y de escenarios reales donde transcurrían las películas, entre otras técnicas propias del movimiento neorrealista de mediados del siglo XX, son incorporadas por Buñuel con la misma finalidad que sus homólogos italianos. 
revolucionario y, a la vez, proyectando una mirada interna, genuina y profunda, que fuera un instrumento "tangible" (visible) de este cambio revolucionario, este camino no ha sido una vía por la que hayan transitado apenas otras películas más allá de las producidas por Sanjinés y su grupo. Si bien es cierto que ha habido muchas y diversas representaciones indígenas en gran parte de las películas bolivianas a lo largo de la historia, éstas han sido incorporadas en mayor o menor medida a una cinematografía de corte más comercial, de tipo hollywoodense. Es decir, la mirada que predomina en ellas es más una que mira hacia el mundo indígena que una que mire desde dentro del mismo. Con el resultado que, con esta estrategia de filtración estética y discursiva, este mundo indígena captado por la cámara puede llegar al gran público de manera mediatizada y accesible para éste, que no posee los códigos para descifrar otra cosmovisión. En contraste, la visión compleja, interna y penetrante que transformó el concepto de lo cinematográfico en Sanjinés no crea una tendencia suficientemente sólida en su trascendencia posterior capaz de construir un modo de filmar y de narrar cinematográficamente, como el mismo cineasta lo percibió. Pero, y de manera complementaria, es muy interesante ver cómo el proyecto que Sanjinés fue diseñando desde los años sesenta, de acercamiento al mundo quechua y aymara mediante la cámara, como una herramienta de representación y lucha, queda plasmado en el centro que fundó, a finales de los años ochenta, Iván Sanjinés, hijo del cineasta: el Centro de Educación y Formación Cinematográfica (CEFREC), del que se hablará más adelante.

Volvamos al proceso que experimentan Jorge Sanjinés y su cine, para ver después cómo éste se vincula a la propuesta cinematográfica del CEFREC. A finales de los años sesenta, Sanjinés se dio cuenta de que, si bien sus primeras películas y documentales realizados con su grupo, como Revolución (1963) y la película que dará nombre al grupo, Ukamau (1966), conseguían reflejar y denunciar las injusticias que vivía el mundo quechua y aymara en el contexto de la sociedad boliviana, era imprescindible dar un paso adelante, mediante el cual el cine, más allá de cumplir un papel de representación, se convirtiera en un instrumento de movilización política, es decir en un motor de cambio. En este contexto, se produjo a finales de los años sesenta Yawar Mallku. Esta emblemática película versa sobre la supuesta esterilización de mujeres indígenas en centros médicos del altiplano andino por parte de los "Cuerpos de progreso" estadounidenses -en la ficción cinematográfica- y evoca el conflicto vivido en la época cuando, según denuncia la película, la organización de ayuda al desarrollo de los Estados Unidos llevó a cabo dichas esterilizaciones. Tras el impacto de la película, se abrió una investigación que 
nunca quedó resuelta, pero que, finalmente, llevó a la expulsión de los Cuerpos de Paz del territorio boliviano. De esta manera tan elocuente y eficaz, Sanjinés alcanzaba el objetivo que perseguía: que el cine no sólo creara consciencia social, sino que además llegara a desencadenar la acción política.

Tras este innegable éxito, Sanjinés se propuso dar un paso adelante hacia un objetivo todavía más ambicioso. Había que seguir avanzando en una dirección en la que la ficción cinematográfica se armonizara mucho más con la realidad indígena que la cámara quería penetrar. Para ello, diversas estrategias fueron implementadas, como prescindir prácticamente de actores profesionales, incorporando masivamente a gente común del mundo real, convertidos así en personajes de ficción; la filmación de escenas que se rodaban una sola vez, sin posibilidad de repetición, para dar más fuerza y dramatismo a la acción, como ocurre al inicio de El coraje de un pueblo (1971), donde se reproduce, con testimonios reales, la masacre de mineros la noche de San Juan (24 de junio) de 1967, en el distrito minero de Siglo XX, norte de Potosí, cuando unas unidades del ejército dispararon indiscriminadamente contra los mineros en huelga, causando la muerte a veintisiete de ellos, justificando más tarde que se trataba de sofocar un núcleo subversivo donde se suponía se encontraba el legendario Che Guevara; el uso de escenarios reales, no manipulados estéticamente para la filmación; y el rodaje cámara en mano, técnica que se popularizó en los años sesenta en el cine de corte político y social para proporcionar más inmediatez de las acciones, más realismo de las mismas y poder representar con más profundidad el punto de vista de los personajes. ${ }^{5}$

Estas estrategias conducirán a la consolidación de un cine progresivamente más cercano a la sociedad y cosmovisión quechua y aymara. Este cine más "genuinamente" indígena, supondrá, a su vez, el paulatino alejamiento de un público netamente occidental, lo que comúnmente entendemos por gran público, poco acostumbrado a transitar imaginariamente entre culturas, cuyo acercamiento simbólico y real requiere de la adquisición de claves culturales propias de otras culturas o, en su defecto, del esfuerzo intelectual y de la voluntad para penetrar en mundos ajenos. Las nuevas estrategias usadas por Sanjinés crearán así un producto

\footnotetext{
${ }^{5}$ Con la cámara en mano se filmó en 1960 el documental de Jean Rouch, Crónica de un verano (Chronique d'un été), técnica que se hizo muy popular a partir de entonces para enfatizar el realismo y la proximidad de la ficción. (Abrams 222).
} 
cinematográfico que requerirá de un espectador que comparta o sea capaz de compartir la cultura representada desde el interior de sí misma. En este sentido, esta cinematografía no hará apenas concesiones al espectador occidental, ni pondrá los filtros necesarios para allanar su comprensión y persuadirle cinematográficamente.

En definitiva, Sanjinés se irá acercando progresivamente a un cine más internalizado en los mundos quechua y aymara a los que aspira captar con una narrativa y una estética propias, es decir, mediante una cinematografía que no importe modelos ajenos al mundo indígena, sino que, a través de la dirección de su cámara, convierta este mundo de objeto en sujeto de la misma. En otras palabras, el objetivo es que se produzca una apropiación del medio cinematográfico por parte de sus personajes y su cosmovisión. Una clara muestra de este proceso es La nación clandestina, de 1989, una de las películas más logradas y complejas del cineasta y, sin duda, una de las más sobresalientes del cine boliviano de todos los tiempos. En resumidas cuentas, al llevar a cabo esta penetración en lo andino indígena, Jorge Sanjinés se va alejando de una propuesta cinematográfica más "accesible" a un público que no posee las claves culturales que le permitirían sumergirse en el mundo representado.

En este proceso de acercamiento a los mundos quechua y aymara, y de alejamiento de un cine de gran público y de acceso intelectual más inmediato, se produce una búsqueda de otros espacios fuera del propio cine, entendido éste de manera más tradicional. Creo, en esta línea, que no es demasiado aventurado ver que la creación de un centro como el CEFREC responde en gran medida a esta búsqueda. Una nueva estética y una nueva narrativa requieren también de un nuevo formato de proyección, de representación, en este caso, audiovisual. EI CEFREC se erige, entonces, como una materialización de la idea fundamental que guió toda la obra Jorge Sanjinés y que, en este sentido, da continuidad a su visión. Tal y como se autodefine desde su página web, El CEFREC tiene como "misión fundamental [...] facilitar capacitación técnica en cine y video a los pueblos indígenas de Bolivia y ayudar en la producción y distribución de sus obras. La visión más amplia que rige el CEFREC es conferir poder a la gente por medio del conocimiento cada vez más sofisticado del video y la cinematografía". ${ }^{6}$ Es decir, el mismo principio que guió, desde lo más profundo, la obra de Jorge Sanjinés al entregar las cámaras

\footnotetext{
${ }^{6}$ La página web del CEFREC está disponible en: http://www.nativenetworks.si.edu/esp/rose/cefrec.htm
} 
al mundo que éstas querían captar para obtener el poder de la expresión y, consecuentemente, de la acción, es el que ahora guía el objetivo principal del CEFREC: proporcionar el poder visual de la expresión y representación del mundo indígena a través de los medios audiovisuales.

Siguiendo a Freya Schiwy, en un libro revelador y de título elocuente, Indianizing Film: Decolonization, the Andes, and the Question of Technology (2009), el CEFREC está a la vanguardia de su género en América Latina y supone una aportación invalorable en el desarrollo audiovisual para la representación de los pueblos indígenas de toda la geografía latinoamericana. EI CEFREC, como acabamos de comentar, es un producto palpable e indudablemente exitoso, ${ }^{7}$ que transmite con fidelidad el objetivo principal que anticipó ya en los años sesenta Sanjinés, es decir, el de aproximar la tecnología audiovisual al mundo indígena con la doble finalidad de que éste pueda representarse a sí mismo, desde sí mismo, y de que esta fiel representación, no mediatizada ni por una lengua dominante, ni una mirada hegemónica, ni una estética prevalente, ni, en definitiva, una perspectiva externa, sirva a su vez como arma de poder en la denuncia de las condiciones de marginalidad, injusticia y explotación a las que ha estado sometida la mayor parte de los pueblos originarios desde la llegada de los españoles en el siglo XVI. Consecuentemente, lo audiovisual se convierte en un instrumento de movilización política hecho propio. Sin duda, creo que se puede afirmar que el CEFREC es la puesta en práctica de la visión que Jorge Sanjinés tan firmemente persiguió desde los inicios de su carrera a través de sus películas: es decir, que el mundo quechua y aymara se apropiara de la cámara, la hiciera suya y, a través de ella, hablara en su idioma y desde su cosmovisión. En lugar de que, por lo contrario, y como hemos estado acostumbrados a ver más frecuentemente, el cine se adueñe del mundo indígena para representarlo desde una lengua, una mirada y una perspectiva ajenas a este mundo, colonizando, por lo tanto, el acto de representación.

EI CEFREC trabaja muy de cerca con la Coordinadora Audiovisual Indígena de Bolivia (CAIB), dirigida por el aymara Jesús Tapia. Ambas organizaciones se han colocado a la vanguardia de la formación y de la

\footnotetext{
${ }^{7}$ Claramente demostrado por el impacto que tiene a nivel de Bolivia y de América Latina en su conjunto, principalmente en el área andina, y la gran cantidad de premios y reconocimientos obtenidos. Véase: http://www.nativenetworks.si.edu/eng/purple/awards_honors.htm
} 
producción audiovisual indígenas en América Latina, participando ampliamente en festivales internacionales de cine y audiovisuales de culturas indígenas nativas, con una producción extensa y firme, además de notoriedad en la realización de programas de capacitación en el área cinematográfica y audiovisual. El CEFREC está asociado al Smithsonian National Museum of the American Indians, con sede en la ciudad de Washington, lo cual nos da una dimensión de su proyección más allá de las fronteras bolivianas. Desde su fundación, el CEFREC ha recibido el apoyo de instituciones y organizaciones de cooperación internacional y se ha financiado con fondos del Estado boliviano, recibiendo un impulso importante en los últimos años, con el gobierno del presidente Morales. Fue el CEFREC, precisamente, junto a la CAIB, la entidad que tuvo a su cargo la tecnología audiovisual y radiofónica de las trascendentales reuniones de la Asamblea Constituyente, que se iniciaron en agosto del 2006, con el fin de elaborar una nueva constitución para Bolivia, que sería aprobada el 7 de febrero de 2009. De manera elocuente y simbólica, la actual constitución boliviana, que (por lo menos en discurso) ha puesto en el centro de sí misma el mundo indígena largamente marginado, se elaboró siendo grabada para la posteridad con unas cámaras que comparten la visión de empoderamiento indígena, que rige el CEFREC.

Ahora bien, la pregunta que surge es la siguiente: si bien ha sido posible llevar a cabo con éxito proyectos como el del CEFREC y la CAIB, convertidas hoy en día en entidades que han trascendido las fronteras nacionales y se han convertido en referentes esenciales en su campo en el ámbito latinoamericano, ¿por qué no lo fue, realmente, el dar una sólida continuidad al cine que iniciaron Ukamau y Jorge Sanjinés desde la década de los sesenta? ¿Puede la pantalla grande proyectar exitosamente, en términos de público y divulgación, representaciones concebidas en otras claves culturales que no sean mediatizadas por y para la mirada "occidental"? ¿O más bien se requieren narrativas reconocibles para el público tanto nacional como internacional que consume cine, de tal manera que el mundo indígena se acerque a la cámara en lugar de que sean los propios indígenas los que se apropien de ella, tal y como propuso Sanjinés? Pensando sólo en el contexto andino, tenemos ejemplos que han dado resultados muy positivos y se han aproximado a la meca mundial del cine a través de dicha mediatización. Uno de ellos es Los Andes no creen en Dios, película basada en la novela del mismo nombre, de otro gran cineasta boliviano, Antonio Eguino, compañero de Sanjinés en Ukamau, que participó en Yawar Mallku y en otras muchas películas suyas, y quien también ha desempeñado cargos en la administración cultural a nivel nacional. Un dato interesante y emblemático es que Los Andes 
no creen en Dios optó, aunque sin éxito, a la candidatura para la nominación de mejor película en lengua no inglesa en el certamen de los premios Óscar del 2007. A pesar de que la película deja muchas dudas sobre las representaciones indígenas que proyecta debido a un exceso de filtración estética de tipo hollywoodense, es importante destacar el esfuerzo realizado para crear una gran producción cinematográfica sobre el mundo minero boliviano, protago- nizada por un personaje legendario de la literatura nacional, la Misk'i Simi (en quechua, "la de la boca dulce").

Otros ejemplos paradigmáticos de este tipo de cine que se adentra al mundo andino desde una visión externa son, indiscutiblemente, las dos películas de la peruana Claudia Llosa. A pesar de la polémica suscitada entre el público y la crítica, principalmente peruanos, por tratarse de películas que muchos han visto como una estereotipación degenerada de los quechuas del Perú rural, parece innegable el intento atrevido y exitoso -ambas películas han tenido concurrencia de público y han conseguido premios importantesde proporcionar una versión innovadora del mundo quechua nacional tanto en el sentido estético como en el narrativo. De nuevo, aunque con recursos distintos a los usados por Eguino, Llosa proyectará su visión quechua mediante una cinematografía más "universalizable" que la de Sanjinés, por el uso de elementos como el cuerpo femenino, y una escenografía mediatizada estéticamente, muy específicamente mediante el uso frecuente de primeros planos, que tanto intentará evitar el cineasta boliviano después de Yawar Mallku. ${ }^{8}$ Tanto Madeinusa (2006) como, más recientemente, La teta asustada (2009) -una de las películas favoritas de las nominadas para la candidatura a mejor película en lengua no inglesa para los Óscar de aquel año, galardón que finalmente conseguiría otra película latinoamericana, El secreto en sus ojos (del argentino Juan José Campanella)- son dos ejemplos que muestran otras representaciones andinas que, si bien controversiales, sin duda son propuestas cinematográficas abiertas a interpretación que acercan más claramente el mundo representado a un público, si bien todavía minoritario, sin duda mucho más extenso que el de Jorge Sanjinés fuera del ámbito boliviano.

${ }^{8}$ Es interesante hacer notar que los actores de Yawar Mallku, que no eran profesionales, no se sintieron identificados consigo mismos cuando se vieron proyectados en la pantalla grande. En su continuo proceso de reflexión y crítica, Sanjinés se dio cuenta que la técnica cinematográfica de los primeros planos no estaba en armonía con el ethos comunitario y desindividualizado de los pueblos originarios. A partir de esta película, intentó evitar el uso de los primeros planos. 
Para ir concluyendo, quisiera apuntar a que si bien iniciativas como el CEFREC y la CAIB están, tanto en su conceptualización como en su práctica, en comunión con el mundo indígena por la identificación de éste con la cámara fílmica a través de la cual se representa, el hecho de que el cine desarrollado por Ukamau y Jorge Sanjinés no haya originado una tendencia cinematográfica que se hubiera incorporado en mayor escala al cine latinoamericano e internacional, concurrido por un público extenso, es sintomático de que lo que es percibido fuera de un ámbito cultural comúnmente categorizado como occidental -es decir, lo otro, lo subalterno, lo indígenano puede ser hablado, ni puede ser mirado en los mismos términos que otras propuestas estéticas y discursivas más cercanas culturalmente a una visión predominantemente occidental, sino que transita en una vía que corre paralela a la avenida central por donde transcurren las películas vinculadas a la hegemonía cinematográfica. De manera que, a pesar de las ayudas y apoyos que los proyectos pro indígenas puedan recibir en Bolivia, en especial en este momento, con el gobierno de Morales, su existencia tiene lugar en una esfera marginal, quedando así relegada a un espacio compartimentado y de clara diferenciación, donde se inscribe lo indígena, como una categoría aparte. Por lo tanto, y bajo esta mirada, estaríamos ante propuestas cinematográficas y audiovisuales que siguen ocupando un espacio distintivamente periférico, aunque incorporado en un área en la que esta marginación con respecto a los espacios hegemónicos haya creado sus propias áreas de poder.

Si volvemos a la idea inicial del impacto del cine en las décadas que van de los años treinta hasta alrededor de los años setenta, cuando éste mantiene, prácticamente, el monopolio de los medios de comunicación de masas audiovisuales, podemos concluir además que, sin duda, desde que surgió la televisión, en la década de los años 50, hasta la sofisticación y proliferación de otros medios vinculados a las redes de tecnología virtual como el Internet y las redes sociales de facebook o twitter, el papel exclusivo del cine como medio de comunicación de masas ha sido radicalmente reformulado, habiéndose abierto nuevas vías de interrelación individual y social de consecuencias todavía inimaginables, como se ha revelado recientemente con el impacto de estos medios en las revoluciones que países como Túnez, Egipto, Libia y Siria, han experimentado en los años 2011 y 2012.

Muy cautelosamente, se podría decir que en un principio la función de las nuevas tecnologías en la política activa es más la de coordinación y divulgación, que la de concienciación, objetivo que Sanjinés, junto a otros cineastas a nivel latinoamericano e internacional, otorgaron al cine, en su propuesta de crear un arte movilizador. Aún así, y a sabiendas de que estas diversas funciones no pueden ser drásticamente separadas unas de otras, ya 
que están estrechamente interconectadas, sin duda el impacto y alcance de las redes sociales nos sitúan en un nuevo paradigma en cuanto al papel de los medios de comunicación en el mundo actual y añade un nuevo interrogante sobre la vigencia de las propuestas cinematográficas del gran director boliviano, Jorge Sanjinés. Tal vez, estemos ante un nuevo planteamiento sobre la posibilidad de que se emitan voces subalternas y de que éstas sean escuchadas y proyectadas desde sí mismas, sin mediación, ni negociación real o simbólica. Estamos ya frente a un nuevo contexto de comunicación social que conlleva nuevas plataformas de interconexión individual y colectiva, las cuales pueden dar como resultado la creación y uso de medios más accesibles para transmitir las voces acalladas por la historia.

Llegados a este punto, y ante el estreno de Insurgentes hace sólo unos meses, después de que este artículo fuera escrito, es imprescindible retomarlo antes de su publicación para incorporar, aunque sea solamente a nivel de observador, esta emblemática película que, como bien apunta Mauricio Souza, es "la primera película de Sanjinés que es configurada -al menos discursivamente- desde las comodidades de la victoria, no desde la distancia crítica" (Souza 2012), con la implicación de que Sanjinés mediante su película endorsa al presidente Morales y su manera de gobernar. ¿Qué significa, entonces, el hecho esencial de encontrarnos ante una realidad nacional transformada por el gobierno de Morales, en la producción, estética y narrativa cinematográficas? ¿De qué manera la presencia (comentada en la nota 1 de este trabajo) del presidente Morales en el estreno europeo de la película en Madrid aporta consideraciones complementarias para interpretar el sentido final de Insurgentes? ${ }^{9}$

Ante la imposibilidad de proporcionar mi propio análisis de la película, me limitaré a ponerla en el contexto de la crítica que ha acompañado su estreno $y$, sin asumir esta crítica como propia, haré referencia a su inserción

\footnotetext{
${ }^{9}$ Muy a mi pesar y transgrediendo, conscientemente y sin otra alternativa, un principio básico de honestidad académica, las líneas dedicadas a la última película de Sanjinés se escriben a partir del libro electrónico editado recientemente por María Elvira Álvarez et al. (Insurgencias. Acercamiento crítico a "Insurgentes" de Jorge Sanjinés), que aglutina una colección de artículos críticos sobre la película, y el texto de Mauricio Souza referido en la cita anterior, y no desde mi propio análisis de la película a la que, lamentablemente, no he tenido todavía acceso. La mención de Insurgentes en este artículo se hace, entonces, desde la convicción de que enriquece un trabajo escrito con anterioridad al estreno de la película.
} 
en el marco de este artículo. De manera que si bien el argumento central de este texto queda inalterado con esta nueva producción del cineasta, es decir, la idea principal, desarrollada desde el inicio, de que el cine de Sanjinés no ha creado una escuela o tendencia cinematográfica incorporada a la filmografía latinoamericana y universal con un legado amplio de películas y cineastas, más allá del propio Sanjinés, también es cierto que Insurgentes abre una dimensión nueva en la trayectoria del director boliviano, a la vez que cierra una etapa. Según sus críticos, Insurgentes asume acríticamente el desempeño de Morales al frente de Bolivia y ve la presidencia del mismo, como el punto culminante de la lucha histórica de los pueblos andinos originarios de Bolivia. Abre de esta manera una dimensión no vista antes en sus películas, la asunción no crítica de la historia actual. Mientras que, a la vez, cierra y fulmina un ciclo que abarca su vida de cineasta, ciclo caracterizado por la incesante lucha por proveer, desde la pantalla y a través de la cámara, resistencia y reivindicación de los pueblos bolivianos marginados históricamente $y$, al hacerlo, reformular la teoría, la estética y la narrativa cinematográficas. ¿Será que Insurgentes es la última película que Sanjinés pretende hacer $y$, a consciencia, quiere cerrar el círculo y situar su obra completa bajo esta perspectiva, una historia paralela a la propia Historia de Bolivia? ¿Será, tal vez, que los sujetos indígenas de sus películas ya no pueden ser re-presentados en la coyuntura política actual dentro del Estado plurinacional de Bolivia? Como fuere, es evidente que el presidente Morales, encabezando la delegación boliviana en el estreno europeo de Insurgentes en Madrid cierra el ciclo cinematográfico de Sanjinés, independientemente de cuál haya sido la intención final del gran cineasta boliviano.

\section{Bibliografía citada}

ABRAMS, Nathan et al. 2001. Studying Film. London, New York: Bloomsbury Academic.

ÁLVAREZ, María Elvira, et al. 2012. Insurgencias. Acercamientos críticos a "Insurgentes" de Jorge Sanjinés. La Paz: Cinemas Cine (edición digital). [http://www.cinemascine.net/uploads/INSURGENCIAS._Acercamientos_cr\%C3\%ADticos _a_Insurgentes_de_Jorge_Sanjin\%C3\%A9s_.pdf] página descargada el 15 de diciembre 2012.

BIRRI, Fernando. 1988. "Cine y subdesarrollo". Hojas de cine: Testimonios y documentos del nuevo cine latinoamericano. Vol. I. México, DF: SEP, UNAM. 17-22. 
EGUINO, Antonio. 1988. “Neorrealismo en Bolivia, 1978-1979”. Hojas de cine:

Testimonios y documentos del nuevo cine latinoamericano. Vol. I. México, DF: SEP, UNAM. 121-131.

FEDAM. 1999. El cine de Jorge Sanjinés. Santa Cruz: Editorial Imprenta Landívar.

HILTON, Forrest, y Sinclair Thompson. 2007. Revolutionary Horizons. Past and Present in Bolivian Politics. London: Verso.

KING, John. 1990. Magical Reels. A History of Cinema in Latin America. London: Verso.

---. $\quad$ et al., eds. 1993. Mediating Two Worlds. Cinematic Encounters in the Americas. London: British Film Institute.

SÁNCHEZ-H., José. 1999. The Art and Politics of Bolivian Cinema. Lanham, MD: Scarecrow Press.

SANJINÉS, Jorge. 1988. "Problemas de la forma y el contenido en el cine revolucionario". Hojas de cine: Testimonios y documentos del nuevo cine latinoamericano. Vol. I. México, DF: SEP, UNAM. 117-120.

---. y grupo Ukumau. 1979. Teoría y práctica de un cine junto al pueblo. México, DF: Siglo XXI Eds.

SCHIWY, Freyra. 2009. Indianizing Film. Decolonization, the Andes, and the Question of Technology. New Brunswick, New Jersey, and London: Rutgers University Press.

SOUZA, Maurico. 2012. "Ocho y medio Insurgentes: los rituales del "proceso de cambio". Página Siete.bo [http://www.paginasiete.bo/2012-09-2/Cultura/ Destacados/30Cul00102.aspx] página descargada el 15 de diciembre, 2012.

SPIVAK, Gayatri Chakravorty. 2010. "Can the Subaltern Speak"? Reflections on an idea: Can the Subaltern Speak? Rosalind C. Morris, ed. New York: Columbia University Press.

STOCK, Ann Marie, ed. 1997. Framing Latin American Cinema. Contemporary Critical Perspectives. Hispanic Issues Vol. 15. Minneapolis: University of Minnesota Press.

\section{(C) BY-NG-ND}

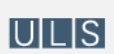

This work is licensed under a Creative Commons AttributionNoncommercial-No Derivative Works 3.0 United States License.

This journal is published by the University Library System of the University of Pittsburgh as part of its D-Scribe Digital Publishing Program, and is cosponsored by the University of Pittsburgh Press. 